\title{
Class III $\beta$-tubulin Expression in Colorectal Neoplasms Is a Potential Predictive Biomarker for Paclitaxel Response
}

\author{
SIDIKA ÖZTOP ${ }^{1,2}$, AYNUR IŞIK $^{2}$, GÜNEŞ GÜNER $^{3,4}$, HAKAN GÜRDAL $^{5}$, \\ ERDEM KARABULUT $^{6}$, ERKAN YILMAZ ${ }^{1}$ and AYTEKIN AKYOL ${ }^{2,3,7,8}$ \\ ${ }^{1}$ Biotechnology Institute, Ankara University, Ankara, Turkey; \\ ${ }^{2}$ Hacettepe University Transgenic Animal Technologies Research and Application Center, Ankara, Turkey; \\ ${ }^{3}$ Department of Pathology, Hacettepe University Faculty of Medicine, Ankara, Turkey; \\ ${ }^{4}$ Mardin State Hospital, Mardin, Turkey; \\ ${ }^{5}$ Department of Medical Pharmacology, Ankara University Faculty of Medicine, Ankara, Turkey; \\ ${ }^{6}$ Department of Biostatistics, Hacettepe University Faculty of Medicine, Ankara, Turkey; \\ ${ }^{7}$ Tumor Pathology Division, Hacettepe University Cancer Institute, Ankara, Turkey; \\ ${ }^{8}$ Hacettepe University Molecular Pathology Research and Application Center, Ankara, Turkey
}

\begin{abstract}
Background/Aim: The challenges of cololorectal cancer (CRC) management include prediction of outcome and drug response or chemoresistance. This study aimed at examining whether $\beta$ III-tubulin (TUBB3), present in various types of normal tissues and cancer, is a biomarker for the response of colorectal neoplasms to paclitaxel. Materials and Methods: Six tissue microarrays (TMAs) including 14 colon mucosa, 78 polyps and 202 CRCs were constructed. Assessment of TUBB3 expression was performed by immunohistochemistry, and it was scored as negative, focal and positive. In the HCT116 cell line, TUBB3 expression was silenced with siRNA. Paclitaxel toxicity was evaluated in TUBB3-silenced and control HCT116 cell lines. Results: The non-neoplastic colon mucosa was negative for TUBB3, while some of colon adenomas and CRCs expressed TUBB3 in various levels from focal to diffuse. TUBB3-expressing CRCs tended to have poor prognosis and silencing of TUBB3 sensitized the cells to paclitaxel. Conclusion: TUBB3 was expressed in a subgroup of colorectal neoplasms. Suppression of TUBB3 potentialy sensitizes neoplastic cells to taxanes.
\end{abstract}

\footnotetext{
*Part of these data were presented in the 1st International Congress on Cancer and Ion Channels, Sanliurfa, Turkey, September, 21-23, 2017.

Correspondence to: Aytekin Akyol, MD, Associate Professor of Pathology, Hacettepe University Department of Pathology, Sihhiye, 06100, Ankara, Turkey. Tel: +90 3123051555 ext. 119, e-mail: aytekina@ hacettepe.edu.tr ORCID: 0000-0002-4075-3475
}

Key Words: TUBB3, colorectal cancer, paclitaxel, biomarker.
Colorectal cancer (CRC) is a significant healthcare problem. Colorectal carcinogenesis is a complex process in which many molecular pathways are dysregulated. CRCs orginate from normal colon epithelium via accumulation of various genetic and epigenetic alterations (1). Effective screening can detect and eliminate precursor neoplastic lesions in the colon and rectum. In the management of advanced tumors, surgical resection is the main treatment of choice. Metastatic CRCs require treatment with adjuvant chemotherapy with or without combinations of targeted therapeutics (2). Intratumoral and intertumoral variations constitute the main challenge for effective management of these neoplasms. However, a better understanding of tumoral heterogeneity paves the way to novel strategies of patient-specific cancer treatment options (3).

The eukaryotic cell cytoskeleton is composed of three cytoskeletal polymers; actin filaments, intermediate filaments, and microtubules (4). Actin-microtubule crosstalk is important for many cellular processes such as cell division, migration, axon specification and polarity (5). Microtubules (MT) are non-covalent polymers that are dynamically assembled from heterodimers of alpha and beta tubulin. Beta tubulin is a broad gene family composed of many isotypes located on different chromosomes $(6,7)$. Beta tubulin hydrolyzes GTP during polymerization (8). Microtubuleassociated proteins (MAPs) regulate microtubule dynamics and tubulin conformation (9). Class III $\beta$-tubulin ( $\beta$ IIItubulin, TUBB3) is encoded by the TUBB3 gene and is expressed in normal neural tissues, during embryogenesis and neoplastic tissues. $\beta$ III-tubulin expression is present in many neural and non-neuronal epithelial neoplasms $(10,11)$. A monoclonal antibody detecting $\beta$ III-tubulin (TUJ1), available since 1989, presented $\beta$ III-tubulin as a neuronal marker (12). 
Earlier studies supported the hypothesis that $\beta$ III-tubulin is an important marker for neurogenesis and neural tumors (13, 14). Missense mutations in TUBB3 cause the TUBB3 syndrome; impairment in axon guidance results in a spectrum of nervous system disorders (15).

MTs are dynamic structures and during mitosis form mitotic spindles. Hence MT binding drugs show their antiproliferative effect by blocking mitosis. Mitotic arrest causes apoptosis of neoplastic cells. Microtubule-targeting agents have some neurological and hematological toxicities (16-18). Drug resistance is a common problem for many conventional chemotherapeutics (19). Several drug resistance mechanisms are considered for microtubule-targeting agents. MAPs and beta tubulin isotype expression could be related to this resistance $(20,21)$. There is some evidence, from reports on several cancer types, suggesting that $\beta$ III-tubulin could be a biomarker for drug resistance (22-24). In this study, the function of TUBB3 expression in healthy colon mucosa, various types of colon polyps and CRCs was addressed by immunohistochemistry and the effect of silencing expression of TUBB3 in the sensitivity of HCT116 CRC cells to paclitaxel treatment was evaluated.

\section{Materials and Methods}

Patients and tissue micro-arrays. Four tissue micro-arrays (TMAs) were constructed from formalin-fixed, paraffin embedded (FFPE) archival samples of $202 \mathrm{CRC}$ patients that contained two $1 \mathrm{~mm}$ spots of representative tumour tissue of various histological subtypes and 14 samples of non-neoplastic colon mucosa. Two TMAs were constructed with $3 \mathrm{~mm}$-wide cores from FFPE blocks of 78 colon polyps with various histological diagnoses as follows; tubular $(n=37)$, tubulovillous $(n=8)$, traditional serrated $(n=18)$, sessile serrated $(n=1)$, serrated adenomas $(n=2)$, hyperplastic $(n=6)$, hamartomatous $(n=4)$, inflammatory fibroid $(\mathrm{n}=1)$ and inflammatory $(\mathrm{n}=1)$. Preparation of a FFPE tissue block of the HCT116 cell line and details for construction of TMAs have been previously described (25). All patient samples were retrieved from the archive of the Department of Pathology of Hacettepe University from cases reported between 2004 and 2016, and clinicopathological features of each case were obtained from Hacettepe University Hospital's pathology report and information system. Ethical approval for this study was obtained from the Non-Interventional Clinical Research Ethics Committee of Hacettepe University (GO 16/720-03 and HEK 12/147-22).

Immunohistochemistry. 4-micron-thick sections from six TMA blocks and the HCT116 cell line block were prepared for immunohistochemistry. Following deparaffinization with xylene, hydration was performed by graded ethanol washes $(96 \%, 90 \%$, and $70 \%$, respectively). After endogenous peroxidase blockage and antigen retrieval, the primary antibody for TUBB3 (clone TUJ1; ab14545, Abcam; Cambridge, MA, USA, 1/500) was applied to the slides. Incubation with a biotinylated secondary antibody solution (UltraVision Detection System Large Volume Anti-Polyvalent, HRP, Thermo Fisher Scientific) was performed for $30 \mathrm{~min}$ at room temperature. Then sections were incubated with streptavidin peroxidase for $30 \mathrm{~min}$. Slides were developed with 3,3'-Diaminobenzidine (DAB) and haematoxylin was used for counterstaining. Two pathologists (A.A., G.G), who were blinded to the clinical data of patients, assessed the expression of TUBB3. Staining in peripheral nerves on the TMA slide served as an internal positive control. Staining results were categorized into three groups as; negative ( 0 ; no staining), focally positive (f; staining of less than $20 \%$ of cells) and positive (1; staining of more than $20 \%$ of cells).

Cell culture and siRNA transfection. HCTT116 cell line was cultured in Dulbecco's modified Eagle's medium-F12 (DMEM-F12, L0092-500; Biowest, Nuaillé, France) containing 10\% fetal bovine serum (Biowest, Nuaillé, France) and $1 \%$ penicillin/streptomycin (Biowest) at $37^{\circ} \mathrm{C}$ in a humidified incubator with $5 \% \mathrm{CO}_{2}$ (HCT116 was kindly provided by Dr. Sreeparna Banerjee - Middle East Technical University, Ankara, Turkey). Small interfering RNA (siRNA) for TUBB3 (ON-TARGETplus Smart Pool TUBB3 siRNA, Dharmacon, Lafayette, USA) and non-targeting control siRNA (ONTARGETplus Non-targeting Control Pool, Dharmacon, Inc.) were transfected using Dharmafect I Transfection Reagent according to the manufacturer's instructions. One day prior to transfection, cells were seeded at $5 \times 10^{4}$ cells per well in 12 well plates or $5 \times 10^{3}$ cells per well in 96-well plates and cells were transfected with TUBB3or control siRNA and further incubated for 24,48 , or $72 \mathrm{~h}$.

RNA extraction, $c D N A$ synthesis and quantitative real-time PCR ( $q R T$ $P C R$ ). Total RNA was purified from cultured cells and fresh frozen colon cancer samples using the TRIzol reagent (Thermo Fisher Scientific). RNA concentration was measured by NanoDrop ND-2000 spectrophotometer (NanoDrop Technologies, Wilmington, DE, USA). cDNA synthesis was performed by High Capacity cDNA Reverse Transcription kit (Thermo Fisher Scientific) with random primers. The resulting cDNA was used for qRT-PCR by the Luminaris Color HiGreen Low ROX qPCR Master Mix (2X) (Thermo Fisher Scientific). cDNA samples from the CRC cell lines Caco-2, DLD-1, HT-29, Lovo, LS174T, HCT116, SW480, RKO and SW837 were obtained in previous studies (supplemented by A.A. from his postdoctoral studies). The cDNA products were amplified using specific primers for TUBB3 (forward: 5'-GGCCAAGGGTCAC TACACG-3' and reverse: 5'-GCAGTCGCAGTTTTCACACTC-3'). HPRT1 (forward: 5'-TGACACTGGCAAAACAATGCA-3' and reverse: 5'-GGTCCTTTTCACCAGCAAGCT-3') were used as a normalisation control. All reactions were run on a Stratagene Mx3005P thermocycler (Agilent Technologies) with a 10-min hot start at $95^{\circ} \mathrm{C}$ followed by 40 cycles of a 3-step thermocycling programme: denaturation, $15 \mathrm{sec}$ at $95^{\circ} \mathrm{C}$; annealing, $30 \mathrm{sec}$ at $60^{\circ} \mathrm{C}$; and extension, $30 \mathrm{sec}$ at $72^{\circ} \mathrm{C}$. Melting curves $\left(60-95^{\circ} \mathrm{C}\right)$ were examined to verify that a single product was amplified. All reactions were performed in duplicate, and relative expression levels were determined by the $\Delta \mathrm{CT}$

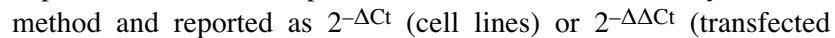
HCT116 cells).

Western blot. HCT116 cell lysates were prepared with the radioimmunoprecipitation assay (RIPA) buffer supplemented with protease inhibitor cocktail (Sigma-Aldrich). The total protein concentration of the soluble extract was determined using the bicinchoninic acid (BCA) kit (Thermo Fisher Scientific). $30 \mu \mathrm{g}$ of total protein sample was mixed with $6 \mathrm{X}$ sample buffer and heated for $10 \mathrm{~min}$ at $95{ }^{\circ} \mathrm{C}$. Protein was electrophoresed on $10 \%$ SDSPAGE for $1.5 \mathrm{~h}$ at $120 \mathrm{~V}$ constant voltage, and then transferred onto polyvinylidene difluoride (PVDF) membranes (BIO-RAD) for $1.5 \mathrm{~h}$ at $90 \mathrm{~V}$ constant voltage. Membranes were incubated for $1 \mathrm{~h}$ at 

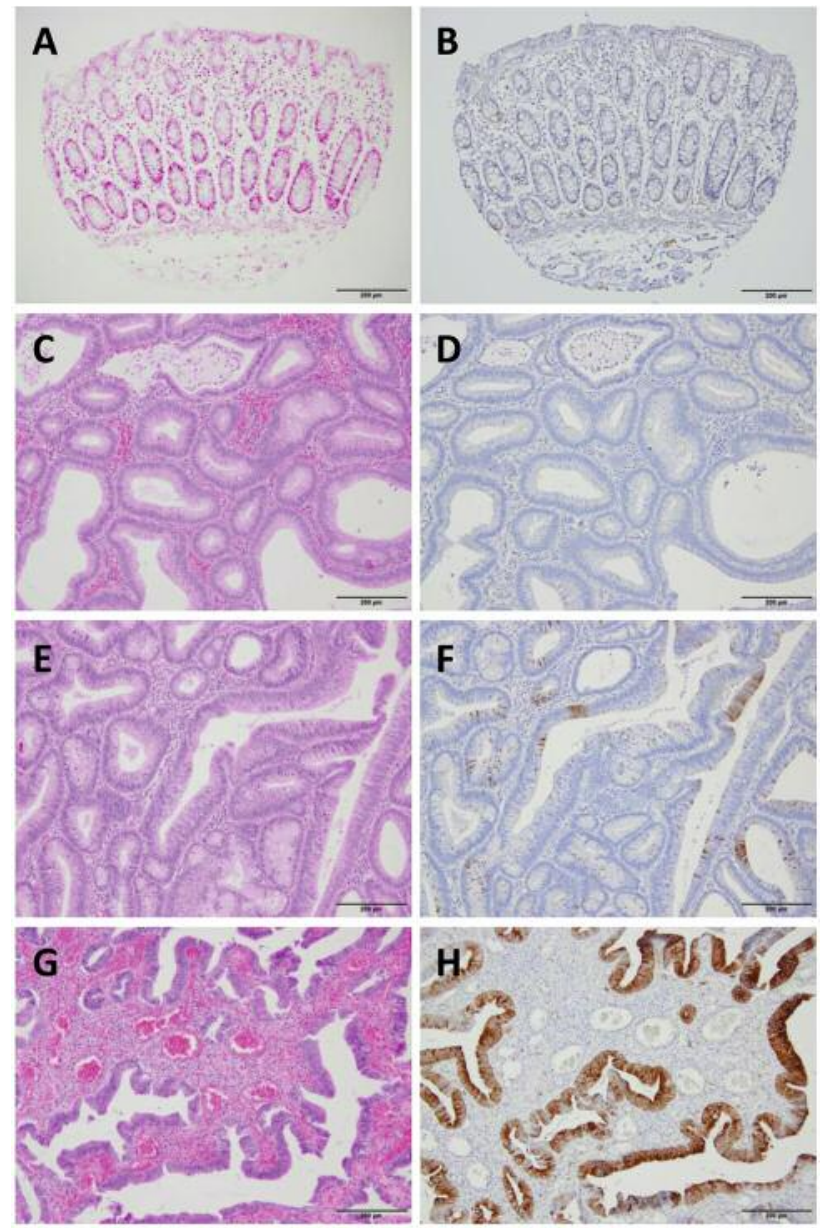

Figure 1. TUBB3 expression in colon mucosa and colonic adenomas was examined by immunocytochemistry. Non-neoplastic colon mucosa had no TUBB3 expression ( $A: H \& E, B: T U B B 3$ immunostaining). Adenomas had variable levels of TUBB3 staining; none $(C: H \& E, D$ : TUBB3), focal (E: H\&E, F: TUBB3;), and wide-spread (G: $H \& E, H$ : TUBB3). Scale bars, $200 \mu \mathrm{m}$.

room temperature in a blocking buffer (TBS containing $0.1 \%$ Tween 20 and 5\% fat-free milk power) and immunostained with primary antibody against $\beta$ III-tubulin (1:1000 dilution; clone TUJ1; Abcam; ab14545) or $\beta$-actin (1: 20,000; AC-15; Sigma-Aldrich) overnight at $4^{\circ} \mathrm{C}$. Then, the membranes were rinsed with Tris-buffered saline/Tween-20 and incubated with horseradish peroxidaseconjugated secondary antibody (Thermo Fisher Scientific) at a 1:4,000 dilution for $1 \mathrm{~h}$ at room temperature. Immune complexes were visualized by enhanced chemiluminescence detection (SuperSignal West Pico Chemiluminescent Substrate, Thermo Fisher Scientific).

Paclitaxel treatment and cell viability assay. To assess the effect of paclitaxel in the context of TUBB3 silencing, HCT116 cells were transfected with siRNA in 96 well plates for $24 \mathrm{~h}$, after that were treated with paclitaxel at various concentrations $(2.5 \mathrm{nM}, 5 \mathrm{nM}, 10$ $\mathrm{nM}, 20 \mathrm{nM}$ and $50 \mathrm{nM}$ ) for $48 \mathrm{~h}$. Following treatment with paclitaxel
Table I. Main clinicopathological characteristics of patients with CRC represented in tissue microarrays.

\begin{tabular}{lc}
\hline Characteristic & $\mathrm{n}(\%)$ \\
\hline Age (years) [n=202], median (range) & $62.2(24-93)$ \\
Gender & \\
Female & $70(34.65)$ \\
Male & $132(65.34)$ \\
Tumor location & \\
Right colon & $66(32.67)$ \\
Left colon & $120(59.40)$ \\
Other/undetermined & $14(6.93)$ \\
Synchronous & $2(0.99)$ \\
Total & 202 \\
Tumor size* median (range, cm) & $5.52(1.7-16)$ \\
Stage** & \\
I & $12(7.50)$ \\
II & $54(33.75)$ \\
III & $45(28.13)$ \\
IV & $49(30.62)$ \\
Status ${ }^{+}$ & $147(72.87)$ \\
Alive & $54(27.13)$ \\
Deceased & $1201(5-4978)$ \\
Follow-up duration***(days), median (range) & \\
Mismatch repair (MMR) status & \\
dMMR & $39(20.20)$ \\
pMMR & $154(79.80)$ \\
TUBB3 immunostaining & \\
Negative & $72(37.89)$ \\
Focal & $74(38.94)$ \\
Positive & $44(23.15)$ \\
\hline
\end{tabular}

+Known for 201/202 cases (99.50\%); \#known for 193/202 cases (95.54\%); *known for $187 / 202$ cases $(95.57 \%)$; **known for $160 / 202$ cases $(79.20 \%)$; ***known for $198 / 202$ cases $(98.01 \%)$.

for $48 \mathrm{~h}$ cell viability of non-transfected, control siRNA or TUBB3siRNA transfected cells was examined using the WST-1 assay (Roche Applied Science) according to the manufacturer's recommendations. Absorbance was subsequently determined using a microplate ELISA reader (SpectraMax Plus 384; Molecular Devices, Sunnyvale, CA, USA) and analysed with SoftMax Pro Software (Molecular Devices) applying the wavelengths $450 \mathrm{~nm}$ for measurements and $600 \mathrm{~nm}$ as reference. Triplicate wells were used for each experiment and all experiments were conducted at least in triplicate.

Statistical analysis. IBM SPSS Statistics for windows ver. 23.0 software was used for statistical analysis. Association between TUBB3 protein expression and other variables such as gender, age, metastasis status, and right/left colon involvement were analysed using Pearson chi-square test. The relationship between TUBB3 expression and survival was analyzed by the survival curves drawn using the Kaplan-Meier method. The log-rank test was used to assess whether there was a difference between the survival curves of the groups. The $\mathrm{IC}_{50}$ values were defined as the concentration of drug required for $50 \%$ cell survival, and were calculated using a logistic regression. Changes between multi-groups were performed with twoway ANOVA. Results were expressed as mean \pm SD. A $p$-value of 0.05 or less was considered statistically significant. 

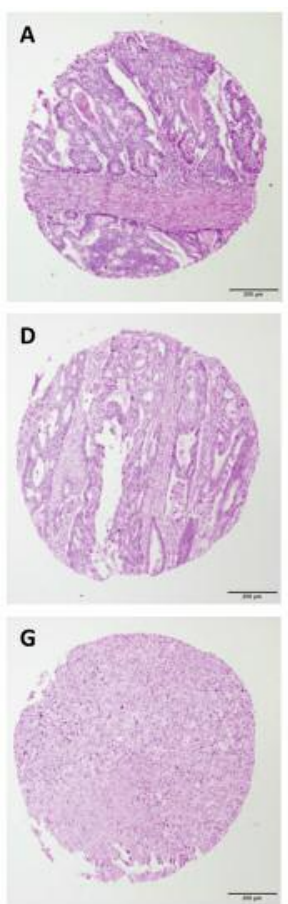
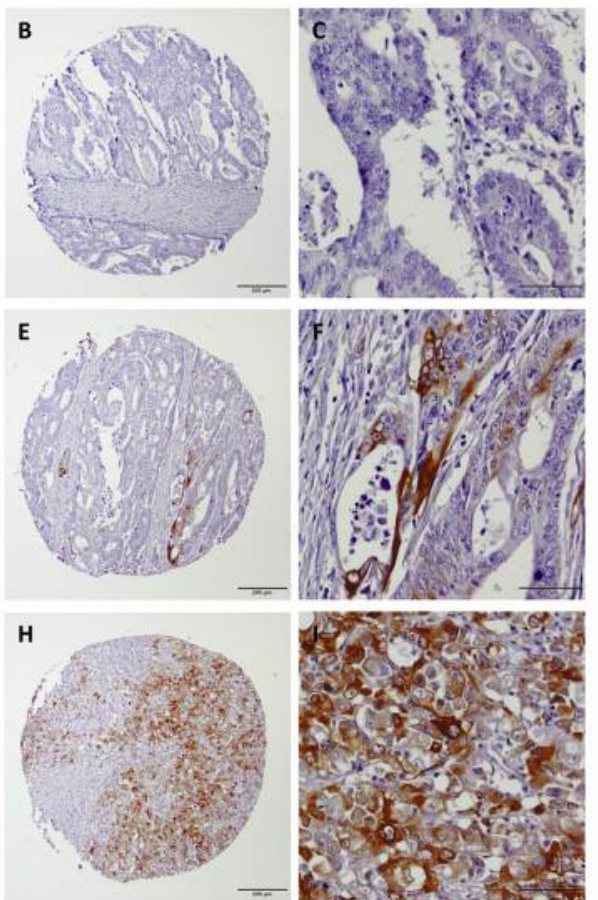
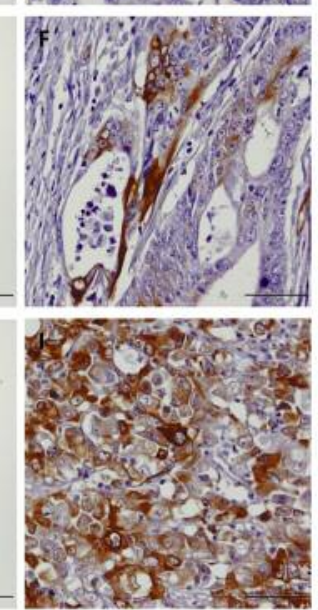

J

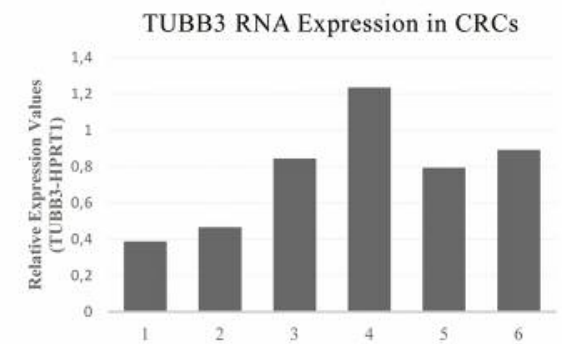

K

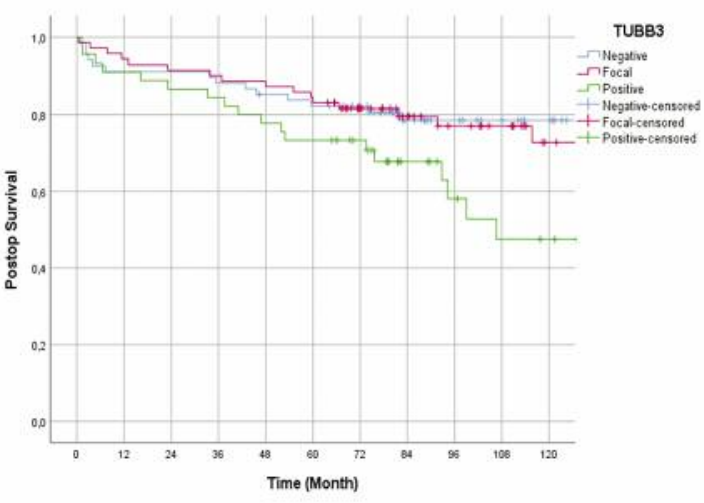

Figure 2. Immunohistochemical evaluation of TUBB3 expression in colorectal carcinomas and survival analysis of patients based on their relative TUBB3 expression in cancer tissues. Lack of TUBB3 expression ( $A: H \& E, B-C: T U B B 3)$, focal TUBB3 expression (D: H\&E, E-F:TUBB3) and high TUBB3 expression (G: H\&E, H-I: TUBB3) was demonstrated on TMA cores (Scale bars; $200 \mu \mathrm{m}, 200 \mu \mathrm{m}$ and $50 \mu \mathrm{m}$, respectively). qPCR data for relative TUBB3 RNA expression in primary colon cancers in respect to their immunohistochemical staining status (1-2: TUBB3 negative, 3-5: focal TUBB3 positive and 6; high TUBB3 expression in immunohistochemistry) (J). Kaplan-Meier curves depicting the postoperative survival of TUBB3 negative, focally positive and positive colorectal carcinoma cases. TUBB3-positive cases (those with more than 20\% tumoral positivity) tend to have a less favorable survival profile than others, yet this association did not reach statistical significance $(K)$.

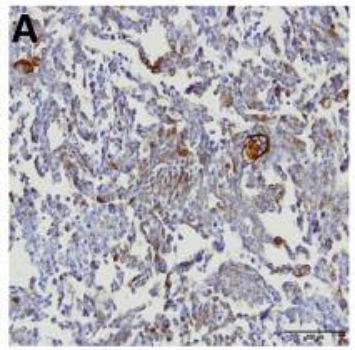

B

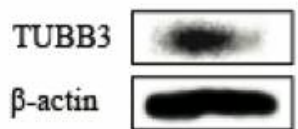

C

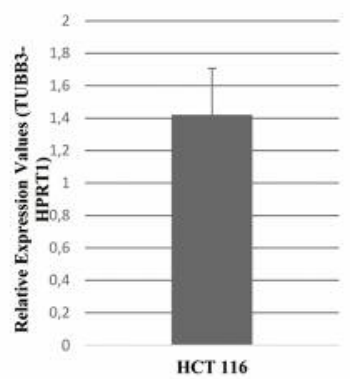

D

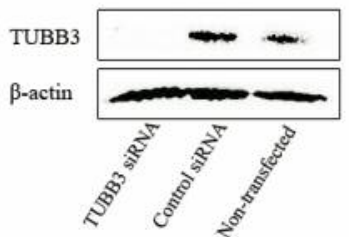

E

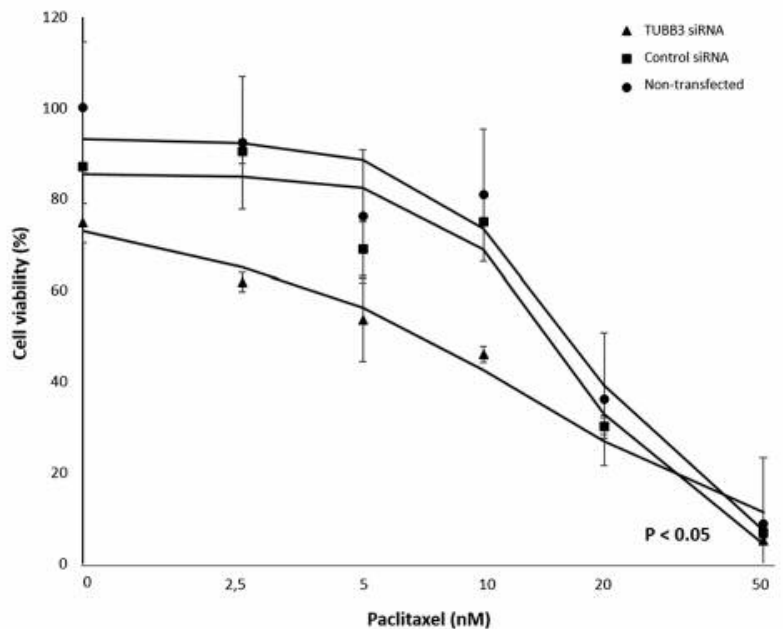

Figure 3. TUBB3 expression of HCT116 cell line was demonstrated by immunohistochemistry (A: scale bar, 100um), western blot (B) and qPCR (C). Silencing of TUBB3 achieved by siRNA transfection. Loss of protein was demonstrated by western blot (D). HCT116 cell lines treated with TUBB3-siRNA had a higher death rate upon the administration of paclitaxel compared to siRNA controls and non-transfected cell lines (E). 


\section{Results}

TUBB3 expression in colon mucosa, adenomas and CRCs. Lack of TUBB3 expression in the non-neoplastic colon mucosa was observed in all cases $(n=14$, Figure $1 \mathrm{~A}$ and B). In our series, colon polyps possessed different levels of TUBB3 expression. Among colon polyps, $24.4 \%(\mathrm{n}=19)$ were negative and $75.6 \%$ $(\mathrm{n}=59)$ were positive for TUBB3. $15.5 \%$ of adenomatous polyps (combination of tubular and tubulovillous adenomas) were negative (Figure 1C, D), and 84.5\% (71\% focal; Figure 1E, F and $13.5 \%$ strong; Figure $1 \mathrm{G}, \mathrm{H}$ ) were positive for TUBB3 expression. TUBB3 positivity was significant in adenomatous lesions $(p<0.05)$. TUBB3 expression was not statistically significant in other colon polyp subtypes. Thereafter, evaluation of TUBB3 expression by immunohistochemistry in CRC TMAs was performed. Out of 202 cases, 12 cases were excluded because of technical problems such as tissue slough-off. In the remaining $190 \mathrm{CRC}$ cases, $37.9 \%(\mathrm{n}=72)$ were negative (Figure $2 \mathrm{~A}-\mathrm{C})$ and $62 \%(\mathrm{n}=118)$ were positive for TUBB3 expression. Focal positivity was observed in $39 \%$ of cases $(n=74)$ and strong expression in $23,1 \%(n=44)$ of cases (Figure 2D-F and 2G-I, respectively). In addition, qPCR evaluation of 6 CRC cases with different TUBB3 immunohistochemistry staining scores were further analyzed for RNA expression (Figure 2J). No statistically significant association between TUBB3 expression and gender, age, tumor localization, and metastasis status was observed $(p>0.05)$. Major clinicopathological features of patients are summarized in Table I. In addition, it was observed that TUBB3 expression was not associated with survival in CRC patients involved in the study $(p>0.05)$, but CRCs with TUBB3 expression tended to have poor prognosis (Figure 2K).

TUBB3 expression in HCT116 cell line and transient silencing by siRNA. In order to perform TUBB3 suppression experiment, nine CRC cell lines (Caco-2, DLD-1, HT-29, LoVo, LS174T, HCT116, SW480, RKO and SW837) were screened by qPCR to identify those with high TUBB3 expression. HCT116, SW837 and LoVo showed high TUBB3 expression; SW480, DLD-1 and Caco-2 showed moderate TUBB3 expression; RKO, HT-29 and LS174T showed low TUBB3 expression. Our results were evaluated using the data from Expression Atlas - EMBL-EBI (https://www.ebi.ac.uk/gxa/home). Based on these two observations, the HCT116 colon cell line, as a high TUBB3 expressing cell line, was selected for TUBB3 silencing. Expression of TUBB3 in HCT116 cells was demonstrated by immunohistochemistry (Figure 3A), western blot (Figure 3B) and qRT-PCR analysis (Figure 3C). After that, TUBB3 was transiently silenced in HCT116 cells. For that purpose, initially, 3 different siRNA concentrations were tested to determine the amount of siRNA that would maximally silence the TUBB3 expression. $48 \mathrm{~h}$ after siRNA transfection with $12.5 \mathrm{nM}, 25 \mathrm{nM}$ and $50 \mathrm{nM}$ of siRNA, total RNA was isolated from the cells and the levels of $T U B B 3$ expression were analyzed by qRT-PCR. TUBB3 expression decreased by $41.4 \%, 73.7 \%$ and $96.3 \%$, respectively. The experiment was repeated with $50 \mathrm{nM} T U B B 3$ siRNA, and western blot was performed by using cell lysates from these cells at $72 \mathrm{~h}$ after transfection (Figure 3D). Effective silencing of the TUBB3 expression in the HCT116 cell line was achieved by $50 \mathrm{nM} T U B B 3$ siRNA. Then, the effect of TUBB3 silencing on cell proliferation was examined by proliferation assay, $48 \mathrm{~h}$ after TUBB3 siRNA transfection. An up to $25 \%$ decrease of proliferation compared to the non-transfected cells was observed. This decrease in proliferation was statistically significant $(p<0.05)$, and demonstrated that TUBB3 expression is associated with the proliferation of HCT116 cells.

Silencing of TUBB3 increases sensitivity to paclitaxel. In order to test sensitivity to paclitaxel in the context of TUBB3 silenced cells, TUBB3 silenced and control HCT116 cells were treated with paclitaxel at varying doses and then examined the changes of cell proliferation (Figure 3E). TUBB3 expression was almost completely suppressed in HCT116 cells after treatment with paclitaxel in various concentrations for $48 \mathrm{~h}$. The proliferation of cells treated with 2.5 or $10 \mathrm{nM}$ of paclitaxel was significantly decreased by $38.2 \%$ and $54 \%$ compared to the non-transfected cells $(p<0.05)$, respectively. The effect of $T U B B 3$ siRNA disappeared following treatment with $20 \mathrm{nM}$ of paclitaxel and that the drug affected all three cell groups in almost the same way. At $50 \mathrm{nM}$ of paclitaxel, the viable cell ratio decreased to $5.9 \%$. The $\mathrm{IC}_{50}$ of the paclitaxel effect was $18.43 \pm 0.6 \mathrm{nM}$ in non-transfected control cells and 17.11 \pm 0.6 $\mathrm{nM}$ in control siRNA transfected cells. On the other hand, in cells transfected with $T U B B 3$ siRNA, the $\mathrm{IC}_{50}$ was found to be $10.47 \pm 1.5 \mathrm{nM}$. In the cells transfected with $T U B B 3$ siRNA, the $\mathrm{IC}_{50}$ dose was found to be 1.76-fold lower than the nontransfected control cells.

\section{Discussion}

Microtubule component TUBB3 is expressed in various types of tissues and cancers. Earlier reports stated that TUBB3 is a neural marker and is associated with neuronal tumors. Now it is commonly accepted that a broad range of neoplasms such as breast, lung, ovary, melanoma express TUBB3. Our study was focused on normal colon samples and colonic neoplasms. The normal colon epithelium was found negative for TUBB3, while a fraction of colorectal neoplasms expressed various amounts of TUBB3. Almost $80 \%$ of colon polyps showed a range of TUBB3 expression. In CRC cases, $38 \%$ were negative for TUBB3, while the remaining cases had various degrees of expression. Melling et al. have reported that among 1.619 CRC cases, 79.2\% were positive and $20.8 \%$ negative for TUBB3 expression (26). In another study, among 100 cases of liver metastases from colorectal tumors $35 \%$ were negative and $65 \%$ were 
positive for TUBB3 expression (27). Portyanko et al. found $100 \%$ positivity of TUBB3 expression in CRC specimens $(n=32)$ that included the invasive margin of the tumours (28). Zhao et al. also found TUBB3 positivity to be $95 \%$ in the case of colorectal tumors $(n=111)$ at the invasive margin (29). In some studies, researchers claimed that TUBB3 was expressed at the invasive edges of neoplasms $(28,29)$. In our study, the non-invasive colon adenomas had a varying range of TUBB3 expression. This finding demonstrated that TUBB3 expression may not be a direct marker of invasiveness but it could create tumor heterogeneity and a fraction can, in time, progress to become invasive. Another hypothesis explaining this observation may be that this neoplastic fraction can induce epithelial to mesenchymal transition (EMT). It is known that the TUBB3 associated pathway is connected to stress-induced conversion to EMT and a chemoresistant phenotype (23).

Taxanes are commonly used for the treatment of many types of cancers. However in CRC management, these drugs are not the first-line treatment. Clinical trials for these agents, in the context of metastatic CRC treatment, did not show a significant benefit. Yet, it is known that TUBB3 expression may be associated with taxane resistance in different types of tumors (20). Our data and previous studies demonstrated that most of the CRCs express TUBB3. However, a fraction of CRCs was not found to express TUBB3 (38\% of cases in our series). In order to test whether that suppression of TUBB3 expression could sensitize neoplastic cells to taxane-based treatment, functional assays for paclitaxel toxicity were carried out. siRNA silencing demonstated that the supression of TUBB3 may increase paclitaxel's anti-neoplastic effect on cancer cells. This result highlights the possibility that CRCs devoid of TUBB3 expression may benefit from paclitaxel. In order to test this hypothesis, further controlled clinical trials could be performed for TUBB3-negative advanced CRCs.

In the literature, there are many studies supporting our hypothesis in tumors of various organs. Ploussard et al., after examining the association between TUBB3 expression and docetaxel susceptibility in prostate cancer, suggested that TUBB3 expression may be a molecular marker for identifying cases that may benefit from taxane-derived agents in prostate cancer (30). Akasaka et al. reported that TUBB3 may be a good biomarker for selecting malignant melanomas that may benefit from taxane-derived chemotherapy. Furthermore, TUBB3 immunohistochemistry and chemosensitivity tests may provide useful information for individualized chemotherapy in melanoma cases (31). TUBB3 expression levels in NSCLC (non-small cell lung carcinoma) cases may be a useful biomarker for arranging personalized chemotherapy (32-33). TUBB3 has been reported to be important as a predictive biomarker for cases of taxane-derived chemotherapy in gastric cancers (34-36). It has also been emphasized that TUBB3 can identify breast cancers that may benefit from taxane-derived chemotherapy $(37,38)$. Based on these reports on solid tumor types, TUBB3 can be used as a biomarker to identify cases that may benefit from taxane-derived agents and guide personalized medical treatments. The results of our study indicate that TUBB3 expression is associated with sensitivity to taxane-derived chemotherapy agents in CRC. In our cohort, TUBB3 expression was found to be negative in 38\% of the CRC patients. This ratio represents the target CRC group for which taxane derivative agents can be used. The use of taxane-derived chemotherapeutic agents at low doses in the treatment of these TUBB3-negative cases can be evaluated with further studies.

Our study has also shown a relatively lower overall survival for TUBB3-positive cases than the rest of the CRCs, yet the association did not reach statistical significance. A larger cohort of CRCs with survival data is required to test whether this observation is valid.

Finally, it was demonstrated that TUBB3 expression in CRCs can be determined by immunohistochemistry. There are colorectal neoplasms expressing TUBB3 at various levels, while some of them are completely negative. siRNAmediated silencing of $T U B B 3$ expression, resulted in a significant reduction of cell proliferation by paclitaxel at non-cytotoxic doses. This indicates that the absence of TUBB3 expression directly affects paclitaxel sensitivity. Our data suggest that taxane-derived agents may be considered as treatment options for TUBB3-negative CRCs.

\section{Conflicts of Interest}

Authors declare no conflict of interest regarding this study.

\section{Authors' Contributions}

S.Ö., A.I. and G.G. carried out the experiments. H.G., E.K., E.Y. and A.A. supervise S.Ö. about the findings of this work. A.A. wrote the manuscript with support from S.Ö. and G.G. All Authors discussed the results and contributed to the final manuscript.

\section{Acknowledgements}

This study was funded by The Scientific and Technological Research Council of Turkey (TUBITAK) under the 1001 program with the project number SBAG-113S985.

\section{References}

1 Fearon ER: Molecular genetics of colorectal cancer. Annu Rev Pathol 6: 479-507, 2011. PMID: 21090969, DOI: 10.1146/ annurev-pathol-011110-130235

2 Aziz MA, Yousef Z, Saleh AM, Mohammad S and Al Knawy B: Towards personalized medicine of colorectal cancer. Crit Rev Oncol Hematol 118: 70-78, 2017. PMID: 28917272, DOI: 10.1016/j.critrevonc.2017.08.007 
3 Almendro V, Marusyk A and Polyak K: Cellular heterogeneity and molecular evolution in cancer. Annu Rev Pathol 8: 277-302, 2013. PMID: 23092187, DOI: 10.1146/annurev-pathol-020712163923

4 Pollard TD and Goldman RD: Overview of the cytoskeleton from an evolutionary perspective. Cold Spring Harb Perspect Biol 10, 2018. PMID: 29967009, DOI: 10.1101/ cshperspect.a030288

5 Dogterom $\mathrm{M}$ and Koenderink GH: Actin-microtubule crosstalk in cell biology. Nat Rev Mol Cell Biol, 2018. PMID: 30323238, DOI: $10.1038 / \mathrm{s} 41580-018-0067-1$

6 Sullivan KF: Structure and utilization of tubulin isotypes. Annu Rev Cell Biol 4: 687-716, 1988. PMID: 3058169, DOI: 10.1146/annurev.cb.04.110188.003351

7 Brouhard GJ and Rice LM: Microtubule dynamics: an interplay of biochemistry and mechanics. Nat Rev Mol Cell Biol 19: 451463, 2018. PMID: 29674711, DOI: 10.1038/s41580-018-0009-y

8 Desai A and Mitchison TJ: Microtubule polymerization dynamics. Annu Rev Cell Dev Biol 13: 83-117, 1997. PMID: 9442869, DOI: 10.1146/annurev.cellbio.13.1.83

9 Wieczorek M, Bechstedt S, Chaaban S and Brouhard GJ: Microtubule-associated proteins control the kinetics of microtubule nucleation. Nat Cell Biol 17: 907-916, 2015. PMID: 26098575, DOI: $10.1038 / \mathrm{ncb} 3188$

10 Katsetos CD, Legido A, Perentes E and Mörk SJ: Class III betatubulin isotype: a key cytoskeletal protein at the crossroads of developmental neurobiology and tumor neuropathology. J Child Neurol 18: 851-866; discussion 867, 2003. PMID: 14736079 , DOI: $10.1177 / 088307380301801205$

11 Mariani M, Karki R, Spennato M, Pandya D, He S, Andreoli M, Fiedler P and Ferlini C: Class III $\beta$-tubulin in normal and cancer tissues. Gene 563: 109-114, 2015. PMID: 25839941, DOI: 10.1016/j.gene.2015.03.061

12 Caccamo D, Katsetos CD, Herman MM, Frankfurter A, Collins VP and Rubinstein LJ: Immunohistochemistry of a spontaneous murine ovarian teratoma with neuroepithelial differentiation. Neuron-associated beta-tubulin as a marker for primitive neuroepithelium. Lab Investig J Tech Methods Pathol 60: 390398, 1989. PMID: 2467076

13 Svendsen CN, Bhattacharyya A and Tai YT: Neurons from stem cells: preventing an identity crisis. Nat Rev Neurosci 2: 831-834, 2001. PMID: 11715059 , DOI: $10.1038 / 35097581$

14 Katsetos CD, Herman MM and Mörk SJ: Class III beta-tubulin in human development and cancer. Cell Motil Cytoskeleton 55: 77-96, 2003. PMID: 12740870, DOI: $10.1002 / \mathrm{cm} .10116$

15 Tischfield MA, Baris HN, Wu C, Rudolph G, Van Maldergem L, He W, Chan W-M, Andrews C, Demer JL, Robertson RL, Mackey DA, Ruddle JB, Bird TD, Gottlob I, Pieh C, Traboulsi EI, Pomeroy SL, Hunter DG, Soul JS, Newlin A, Sabol LJ, Doherty EJ, de Uzcátegui CE, de Uzcátegui N, Collins MLZ, Sener EC, Wabbels B, Hellebrand H, Meitinger T, de Berardinis T, Magli A, Schiavi C, Pastore-Trossello M, Koc F, Wong AM, Levin AV, Geraghty MT, Descartes M, Flaherty M, Jamieson RV, Møller HU, Meuthen I, Callen DF, Kerwin J, Lindsay S, Meindl A, Gupta ML, Pellman D and Engle EC: Human TUBB3 mutations perturb microtubule dynamics, kinesin interactions, and axon guidance. Cell 140: 74-87, 2010. PMID: 20074521, DOI: $10.1016 /$ j.cell.2009.12.011

16 Zhou J and Giannakakou P: Targeting microtubules for cancer chemotherapy. Curr Med Chem Anti-Cancer Agents 5: 65-71, 2005. PMID: 15720262
17 Dumontet $\mathrm{C}$ and Jordan MA: Microtubule-binding agents: a dynamic field of cancer therapeutics. Nat Rev Drug Discov 9: 790-803, 2010. PMID: 20885410, DOI: $10.1038 /$ nrd3253

18 Weaver BA: How taxol/paclitaxel kills cancer cells. Mol Biol Cell 25: 2677-2681, 2014. PMID: 25213191, DOI: 10.1091/mbc.E14-04-0916

19 Wijdeven RH, Pang B, Assaraf YG and Neefjes J: Old drugs, novel ways out: Drug resistance toward cytotoxic chemotherapeutics. Drug Resist Updat Rev Comment Antimicrob Anticancer Chemother 28: 65-81, 2016. PMID: 27620955, DOI: $10.1016 /$ j.drup.2016.07.001

20 Kavallaris M: Microtubules and resistance to tubulin-binding agents. Nat Rev Cancer 10: 194-204, 2010. PMID: 20147901, DOI: $10.1038 / \mathrm{nrc} 2803$

21 Parker AL, Teo WS, McCarroll JA and Kavallaris M: An Emerging Role for Tubulin Isotypes in Modulating Cancer Biology and Chemotherapy Resistance. Int J Mol Sci 18, 2017. PMID: 28677634, DOI: 10.3390/ijms 18071434

22 Mariani M, Shahabi S, Sieber S, Scambia G and Ferlini C: Class III $\beta$-tubulin (TUBB3): more than a biomarker in solid tumors? Curr Mol Med 11: 726-731, 2011. PMID: 21999149

23 Wiemer EAC: Stressed tumor cell, chemosensitized cancer. Nat Med 17: 1552-1554, 2011. PMID: 22146456, DOI: $10.1038 / \mathrm{nm} .2593$

24 Karki R, Mariani M, Andreoli M, He S, Scambia G, Shahabi S and Ferlini C: $\beta$ III-Tubulin: biomarker of taxane resistance or drug target? Expert Opin Ther Targets 17: 461-472, 2013. PMID: 23379899, DOI: 10.1517/14728222.2013.766170

25 Akyol A, Güner G, Özşeker HS, Işık A, Atcı Ö, Uzun S, Atayar E, Ozaltin F, Gedikoğlu G, Sökmensüer C and Fearon ER: An immunohistochemical approach to detect oncogenic CTNNB1 mutations in primary neoplastic tissues. Lab Invest 99: 128-137, 2019. PMID: 30177831, DOI: 10.1038/s41374018-0121-9

26 Melling N, Tsaklakidis AM, Simon R, Stahl P, Bokemeyer C, Terracciano L, Sauter G, Izbicki JR and Marx AH: $\beta$ III-tubulin overexpression is linked to left-sided tumor localization and nuclear $\beta$-catenin expression in colorectal cancer. Cancer Treat Commun 4: 96-102, 2015. DOI: 10.1016/j.ctrc.2015.06.004

27 Tóth C, Sükösd F, Valicsek E, Herpel E, Schirmacher P, Renner M, Mader C, Tiszlavicz L and Kriegsmann J: Expression of ERCC1, RRM1, TUBB3 in correlation with apoptosis repressor ARC, DNA mismatch repair proteins and p53 in liver metastasis of colorectal cancer. Int J Mol Med 40: 1457-1465, 2017. PMID: 28949378, DOI: 10.3892/ijmm.2017.3136

28 Portyanko A, Kovalev P, Gorgun J and Cherstvoy E: beta(III)tubulin at the invasive margin of colorectal cancer: possible link to invasion. Virchows Arch Int J Pathol 454: 541-548, 2009. PMID: 19360438, DOI: 10.1007/s00428-009-0764-4

29 Zhao X, Yue C, Chen J, Tian C, Yang D, Xing L, Liu H and Jin Y: Class III $\beta$-tubulin in colorectal cancer: tissue distribution and clinical analysis of chinese patients. Med Sci Monit Int Med J Exp Clin Res 22: 3915-3924, 2016. PMID: 27771732

30 Ploussard G, Terry S, Maillé P, Allory Y, Sirab N, Kheuang L, Soyeux P, Nicolaiew N, Coppolani E, Paule B, Salomon L, Culine S, Buttyan R, Vacherot F and de la Taille A: Class III beta-tubulin expression predicts prostate tumor aggressiveness and patient response to docetaxel-based chemotherapy. Cancer Res 70: 9253-9264, 2010. PMID: 21045157, DOI: 10.1158/0008-5472.CAN-10-1447 
31 Akasaka K, Maesawa C, Shibazaki M, Maeda F, Takahashi K, Akasaka T and Masuda T: Loss of class III beta-tubulin induced by histone deacetylation is associated with chemosensitivity to paclitaxel in malignant melanoma cells. J Invest Dermatol 129: 1516-1526, 2009. PMID: 19122647, DOI: 10.1038/jid.2008.406

32 Yang YL, Luo XP and Xian L: The prognostic role of the class III $\beta$-tubulin in non-small cell lung cancer (NSCLC) patients receiving the taxane/vinorebine-based chemotherapy: a metaanalysis. PloS One 9: e93997, 2014. PMID: 24705847, DOI: 10.1371/journal.pone.0093997

33 Ohashi T, Yoshimasu T, Oura S, Kokawa Y, Kawago M, Hirai Y, Miyasaka M, Aoishi Y, Kiyoi M, Nishiguchi H, Honda M and Okamura Y: Class III beta-tubulin expression in non-small cell lung cancer: a predictive factor for paclitaxel response. Anticancer Res 35: 2669-2674, 2015. PMID: 25964544

34 Hwang JE, Hong JY, Kim K, Kim SH, Choi WY, Kim MJ, Jung SH, Shim HJ, Bae WK, Hwang EC, Lee KH, Lee JH, Cho SH and Chung IJ: Class III $\beta$-tubulin is a predictive marker for taxane-based chemotherapy in recurrent and metastatic gastric cancer. BMC Cancer 13: 431, 2013. PMID: 24053422, DOI: 10.1186/1471-2407-13-431

$35 \mathrm{Lu} \mathrm{M}$, Gao J, Wang X and Shen L: Expressions of thymidylate synthase, thymidine phosphorylase, class III $\beta$-tubulin, and excision repair cross-complementing group 1 predict response in advanced gastric cancer patients receiving capecitabine plus paclitaxel or cisplatin. Chin J Cancer Res 23: 288-294, 2011. PMID: 23358102, DOI: 10.1007/s11670-011-0288-8
36 Urano N, Fujiwara Y, Doki Y, Kim SJ, Miyoshi Y, Noguchi S, Miyata H, Takiguchi S, Yasuda T, Yano M and Monden M: Clinical significance of class III beta-tubulin expression and its predictive value for resistance to docetaxel-based chemotherapy in gastric cancer. Int $\mathrm{J}$ Oncol 28: 375-381, 2006. PMID: 16391792

37 Tommasi S, Mangia A, Lacalamita R, Bellizzi A, Fedele V, Chiriatti A, Thomssen C, Kendzierski N, Latorre A, Lorusso V, Schittulli F, Zito F, Kavallaris M and Paradiso A: Cytoskeleton and paclitaxel sensitivity in breast cancer: the role of betatubulins. Int J Cancer 120: 2078-2085, 2007. PMID: 17285590, DOI: $10.1002 / \mathrm{ijc} .22557$

38 Yuan SF, Zhu LJ, Zheng WE, Chen H, Wu LL, Zhang W, Sun $\mathrm{HY}$ and Chen WJ: Expression of $\beta$-tubulin III and survivin in advance stage breast cancer correlates with chemotherapeutic effects of docetaxel. Asian Pac J Cancer Prev APJCP 13: 361365, 2012. PMID: 22502701
Received December 27, 2018

Revised January 17, 2019

Accepted January 18, 2019 